\title{
A comparative study on the efficacy of $10 \%$ hypertonic saline and equal volume of $20 \%$ mannitol in the treatment of experimentally induced cerebral edema in adult rats
}

\author{
Hong-Ke Zeng ${ }^{1 * \dagger}$, Qiao-Sheng Wang ${ }^{1,2+}$, Yi-Yu Deng ${ }^{1}$, Wen-Qiang Jiang ${ }^{1}$, Ming Fang ${ }^{1}$, Chun-Bo Chen ${ }^{1}$, Xin Jiang ${ }^{1,3}$
}

\begin{abstract}
Background: Hypertonic saline and mannitol are commonly used in the treatment of cerebral edema and elevated intracranial pressure (ICP) at present. In this connection, 10\% hypertonic saline (HS) alleviates cerebral edema more effectively than the equal volume of $20 \%$ mannitol. However, the exact underlying mechanism for this remains obscure. This study aimed to explore the possible mechanism whereby $10 \%$ hypertonic saline can ameliorate cerebral edema more effectively than mannitol.
\end{abstract}

Results: Adult male Sprague-Dawley (SD) rats were subjected to permanent right-sided middle cerebral artery occlusion (MCAO) and treated with a continuous intravenous infusion of $10 \% \mathrm{HS}, 20 \%$ mannitol or $\mathrm{D}-\left[1-{ }^{3} \mathrm{H}(\mathrm{N})\right]-$ mannitol. Brain water content (BWC) as analyzed by wet-to-dry ratios in the ischemic hemisphere of SD rats decreased more significantly after 10\% HS treatment compared with 20\% mannitol. Concentration of serum $\mathrm{Na}^{+}$ and plasma crystal osmotic pressure of the 10\% HS group at 2, 6, 12 and $18 \mathrm{~h}$ following permanent MCAO increased significantly when compared with $20 \%$ mannitol treated group. Moreover, there was negative correlation between the BWC of the ipsilateral ischemic hemisphere and concentration of serum $\mathrm{Na}^{+}$, plasma crystal osmotic pressure and difference value of concentration of serum $\mathrm{Na}^{+}$and concentration of brain $\mathrm{Na}^{+}$in ipsilateral ischemic hemisphere in the 10\% HS group at the various time points after MCAO. A remarkable finding was the progressive accumulation of mannitol in the ischemic brain tissue.

Conclusions: We conclude that $10 \% \mathrm{HS}$ is more effective in alleviating cerebral edema than the equal volume of $20 \%$ mannitol. This is because 10\% HS contributes to establish a higher osmotic gradient across BBB and, furthermore, the progressive accumulation of mannitol in the ischemic brain tissue counteracts its therapeutic efficacy on cerebral edema.

\section{Background}

Cerebral edema is involved in many neurological diseases such as cerebral ischemia/hemorrhage, brain trauma and brain tumor or abscess [1]. Severe cerebral edema must be managed immediately to prevent brain herniation. Osmotic therapy is a cornerstone in nonsurgical management of intracranial pressure (ICP) induced

\footnotetext{
* Correspondence: zenghongke@vip.163.com

+ Contributed equally

'Department of Emergency \& Critical Care Medicine, Guangdong General Hospital, Guangdong Academy of Medical Sciences, Guangzhou 510080, PR China

Full list of author information is available at the end of the article
}

by various cerebral edema. Its effectiveness depends on: 1) the integrity of the blood-brain barrier (BBB), 2) the reflection coefficient of the osmotic agent, and 3) the osmotic gradient created [2]. $20 \%$ mannitol, as a classical osmotic dehydrating agent, is widely used as a dehydrating agent in clinical patients with cerebral edema. However, because it may lead to hypovolemia, renal dysfunction $[3,4]$, heart failure, electrolyte disturbance and other side effects, there are certain restrictions in clinical practice. In recent years, many studies have shown that $10 \%$ hypertonic saline (HS) may be effective in treatment of all kinds of cerebral edema and intracranial hypertension caused by various causes, including

\section{Biomed Central}


traumatic brain injury [5-8], cerebral stroke [9,10], subarachnoid hemorrhage [11], brain tumors [12], etc. Compared with mannitol, HS is more effective to ameliorate cerebral edema and intracranial hypertension [6-8,10,13-16]. Furthermore, HS remains significantly effective even in situations when use of mannitol had failed [10] or cerebral hernia [17]. However, the specific mechanism by which HS can ameliorate cerebral edema more effectively than equal volume of $20 \%$ mannitol remains unclear. This study sought to determine if $10 \%$ HS administration could decrease cerebral edema more effectively than $20 \%$ mannitol, and if so, whether the efficacy would be associated with a formation of $\mathrm{Na}^{+}$ osmotic concentration gradient between blood and brain tissue. Additionally, we also investigated whether $20 \%$ mannitol could accumulate progressively in the ischemic cerebral tissue. We report here that $10 \% \mathrm{HS}$ decreases brain water content (BWC) more effectively than equal volume of $20 \%$ mannitol. The results suggest that this may be attributed to a formation of $\mathrm{Na}^{+}$osmotic concentration gradient between blood and brain tissue by $\mathrm{HS}$ and progressive accumulation of $20 \%$ mannitol in the ischemic brain tissue.

\section{Methods}

\section{Animals and experimental groups}

Adult male Sprague-Dawley (SD) rats 250-300 g (body weight) (Experimental Animal Center of SUN YAN-SEN University, China) were randomly divided into a shamoperated group $(n=48)$, cerebral ischemic + normal saline treatment group (abbreviated: normal saline group) $(n=48)$, cerebral ischemic $+20 \%$ mannitol treatment group (abbreviated: $20 \%$ mannitol group) $(n=60)$, and cerebral ischemic $+10 \%$ HS treatment group (abbreviated: $10 \%$ HS group) $(n=48)$. Under aseptic surgical conditions, the tail vein was cannulated to facilitate the intravenous (i.v.) infusion of $20 \%$ mannitol, $10 \%$ HS or normal saline. Rats in normal saline group, $20 \%$ mannitol group and $10 \%$ HS group were subjected to permanent right-sided middle cerebral artery occlusion (MCAO). In the sham-operated group, the rats were anesthetized with 5\% Ketamine (FuJian GuTian Pharmaceutical Co., Ltd., China) following which the right common carotid artery (CCA) was exposed but not subjected to MCAO. At $6 \mathrm{~h}$ following MCAO, the rats in sham-operated group and normal saline group were treated with normal saline $(0.3$ $\mathrm{ml} / \mathrm{h}$ ). At the same time point, the rats in $20 \%$ mannitol group and $10 \%$ HS group were treated with a continuous intravenous infusion $(0.3 \mathrm{ml} / \mathrm{h})$ of $20 \%$ mannitol or $10 \%$ HS, respectively, via the tail vein until the end of the experiment. The rats in sham-operated group, normal saline group, $20 \%$ mannitol group and $10 \%$ HS treatment group were further subdivided into four subgroups according to different treatment times: 2, 6, 12 and $18 \mathrm{~h}$.
In addition, 12 of the rats in $20 \%$ mannitol group were also subdivided correspondingly into four subgroups: 2 , 6, 12 and $18 \mathrm{~h}$ following the onset of treatment with $20 \%$ D- $\left[1-{ }^{3} \mathrm{H}(\mathrm{N})\right]$-mannitol (NET101005MC., PerkinElmer, Inc. USA). In this connection, the rats were treated with a continuous intravenous infusion $(50 \mu \mathrm{Ci} / \mathrm{h})$ of D-[ $\left[1-{ }^{3} \mathrm{H}\right.$ (N)]-mannitol via the tail vein until the end of the experiment. The number of rats killed at various time points in different groups is shown in Table 1. Animal handling and experiments were approved by Institutional Animal Care and Use Committee, Guangdong Province, China.

\section{Focal brain ischemia animal model}

In rats subjected to MCAO, they were fasted overnight prior to surgery, but were allowed free access to water. The rats were anesthetized with $5 \%$ Ketamine $(40 \mathrm{mg} /$ $\mathrm{kg}$ ). Rectal temperature was maintained between 37 and $37.5^{\circ} \mathrm{C}$ with a heating lamp throughout the surgical procedures. Focal brain ischemia was induced by the intraluminal suture MCAO method as described previously $[18,19,13]$. Briefly, the right CCA, internal carotid artery (ICA), and external carotid artery (ECA) were exposed through a midline incision of the neck. A 4-0 headend spherical nylon suture was used as an occluder and was inserted via the CCA. For the CCA occlusion route, the proximal portions of the right CCA and ECA were ligated with 5-0 surgical sutures, and the occluder was inserted through an arteriotomy of the right CCA $3 \mathrm{~mm}$ below the carotid bifurcation. The occluder was advanced into the ICA 17 to $19 \mathrm{~mm}$ beyond the carotid bifurcation. Mild resistance indicated that the occluder was properly lodged in the middle cerebral artery (MCA) and thus blocked the blood flow to the artery. Sham-operated rats were subjected to the surgical procedures except for MCAO. Neurologic examinations were performed $6 \mathrm{~h}$ after the onset of occlusion. The neurologic findings were scored on a five-point scale [18]: 0, no neurologic deficit; 1 , a mild focal neurologic deficit (failure to extend left forepaw fully); 2, a moderate focal neurologic deficit (circling to the left); and 3, a severe focal deficit (falling to the left); 4, no spontaneous motor activity (the rats did not walk spontaneously and had a depressed level of consciousness). The rats with neurologic deficit score of 1 to 3 were considered as an effective model.

\section{Assessment of ischemic hemispheric brain edema}

Rats were killed at the end of the experiment by decapitation under deep anesthesia. The brain was quickly removed and gently blotted to remove small quantities of adsorbent moisture and were dissected through the interhemispheric fissure into ipsilateral ischemic and contralateral hemispheres. Brain edema was estimated by comparing wet to dry weight ratios [20,21]. Tissues were weighed with a scale to within $0.001 \mathrm{mg}$. Dry 
Table 1 Number of rats killed at various time points in different groups

\begin{tabular}{|c|c|c|c|c|}
\hline Groups & BWC & Concentration of brain $\mathrm{Na}^{+}$ & Blood parameters & 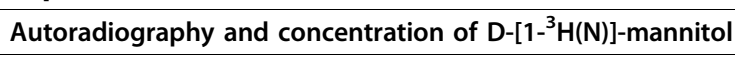 \\
\hline \multicolumn{5}{|c|}{ Sham-operated group } \\
\hline $2 \mathrm{~h}$ & 6 & 6 & 8 & 0 \\
\hline $6 \mathrm{~h}$ & 6 & 6 & 8 & 0 \\
\hline $12 \mathrm{~h}$ & 6 & 6 & 8 & 0 \\
\hline $18 \mathrm{~h}$ & 6 & 6 & 8 & 0 \\
\hline \multicolumn{5}{|c|}{ Normal saline group } \\
\hline $2 \mathrm{~h}$ & 6 & 6 & 8 & 0 \\
\hline $6 \mathrm{~h}$ & 6 & 6 & 8 & 0 \\
\hline $12 \mathrm{~h}$ & 6 & 6 & 8 & 0 \\
\hline $18 \mathrm{~h}$ & 6 & 6 & 8 & 0 \\
\hline \multicolumn{5}{|c|}{$20 \%$ mannitol group } \\
\hline $2 \mathrm{~h}$ & 6 & 6 & 8 & 3 \\
\hline $6 \mathrm{~h}$ & 6 & 6 & 8 & 3 \\
\hline $12 \mathrm{~h}$ & 6 & 6 & 8 & 3 \\
\hline $18 \mathrm{~h}$ & 6 & 6 & 8 & 3 \\
\hline \multicolumn{5}{|c|}{$10 \%$ HS group } \\
\hline $2 \mathrm{~h}$ & 6 & 6 & 8 & 0 \\
\hline $6 \mathrm{~h}$ & 6 & 6 & 8 & 0 \\
\hline $12 \mathrm{~h}$ & 6 & 6 & 8 & 0 \\
\hline $18 \mathrm{~h}$ & 6 & 6 & 8 & 0 \\
\hline
\end{tabular}

weight of the entire ischemic hemispheres was determined after heating the tissue for 3 days at $100^{\circ} \mathrm{C}$ in a drying oven. Tissue water content was then calculated as $\% \mathrm{H}_{2} \mathrm{O}=(1$-dry wt/wet wt $) \times 100 \%[20,21]$.

\section{Assessment of concentration of brain $\mathrm{Na}^{+}$of ischemic hemisphere, serum $\mathrm{Na}^{+}$and plasma crystal osmotic pressure}

Brain tissue was removed as described above. Normal saline at $2 \mathrm{ml} / \mathrm{g}$ ischemic hemisphere brain tissue was then added. The tissue was homogenated by power-driven in the ice, followed by centrifugation at 12,000 rev/ min for 5 min. Finally, concentration of brain $\mathrm{Na}^{+}$of ischemic hemisphere was detected by automatic biochemical analyzer (UniCel DxC 800 Synchron, Beckman Coulter, Inc., USA) in $500 \mu \mathrm{L}$ supernatant. In addition, Four $\mathrm{mL}$ blood samples were drawn from rats under deep anesthesia. The blood samples were then centrifuged (3,000 rev/min for $5 \mathrm{~min}$ ) after standing $2 \mathrm{~h}$. The concentration of serum $\mathrm{Na}^{+}$and plasma crystal osmotic pressure were detected by an automatic biochemical analyzer (UniCel DxC 800 Synchron, Beckman Coulter, Inc., USA) with $500 \mu \mathrm{L}$ supernatant.

Assessment of the non-ischemic and ischemic hemisphere $\mathrm{D}-\left[1-{ }^{3} \mathrm{H}(\mathrm{N})\right]-$ mannitol content by autoradiography and liquid scintillation method Method for autoradiography

Rats were killed at the end of the experiment by decapitation under deep anesthesia. They were perfused transcardially with saline and the brain removed immediately. Coronal frozen sections of the brain of $30 \mu \mathrm{m}$ thickness at the level of the optic chiasma were cut and fixed for $30 \mathrm{sec}$ with anhydrous methanol. Brain sections were immersed in nuclear emulsion N-4 (Fujifilm Corporation, Japan) for $30 \mathrm{sec}$ and then exposed for four weeks in the darkroom. Subsequently the sections were developed, fixed and fully dried. The number of silver grains of the periinfarct brain tissue and the corresponding nonischemic brain tissue was calculated by counting six randomly selected microscopic fields in sections obtained from each rat $(n=3)$ at $\times 20$ objective by a blinded observer.

\section{Liquid scintillation method}

Fifty mg of the peri-infarction brain tissue as well as the corresponding non-ischemic brain tissue at the level of the optic chiasma level was quickly removed. Two hundred $\mu \mathrm{L}$ perchloric acid and $200 \mu \mathrm{L} 30 \%$ hydrogen peroxide were added successively in the brain tissue. The specimen was reacted in the $80^{\circ} \mathrm{C}$ incubator for $30 \mathrm{~min}$ resulting in a homogeneous liquid. After the liquid was cooled to room temperature, $200 \mu \mathrm{L}$ of the liquid was transferred to special bottles for liquid scintillation. In the latter, $2 \mathrm{~mL}$ scintillation fluid and $2 \mathrm{~mL}$ ethanol were added, respectively. The reaction mixture was shaken for a few sec turning it into a clear liquid. The concentration of the D-[1- $\left.{ }^{3} \mathrm{H}(\mathrm{N})\right]$-mannitol was then detected by liquid scintillation analyzer (Tri-Carb 2900TR, PerkinElmer, Inc. USA). 


\section{Data analysis and statistics}

All data were analyzed using the SPSS13.0 statistical software. Different statistical methods were applied according to types of data. Values were expressed as mean \pm standard deviation $( \pm S D)$. Univariate-factor measurement data was analyzed by one-way ANOVA, but two-factor measurement data was analyzed by twoway classification ANOVA. Multiple comparisons were analyzed by LSD method if the data was homogeneity of variance, otherwise they were analyzed by Dunnett's T3 method. Bivariate correlation analysis of measurement data was analyzed by Pearson correlation analysis. The difference was considered statistical significance when $P<0.05$.

\section{Results}

Ipsilateral ischemic hemispheric BWC

Analysis of ischemic hemispheric brain edema revealed that BWC in the ipsilateral ischemic hemispheres of the normal saline group, the $20 \%$ mannitol group and the $10 \%$ HS group at 2, 6, 12 and $18 \mathrm{~h}$ following permanent $\mathrm{MCAO}$ increased significantly when compared with that in the sham operated group $\left({ }^{*} * \& P<0.05\right)$ (Figure 1). Compared with the normal saline group, BWC in the

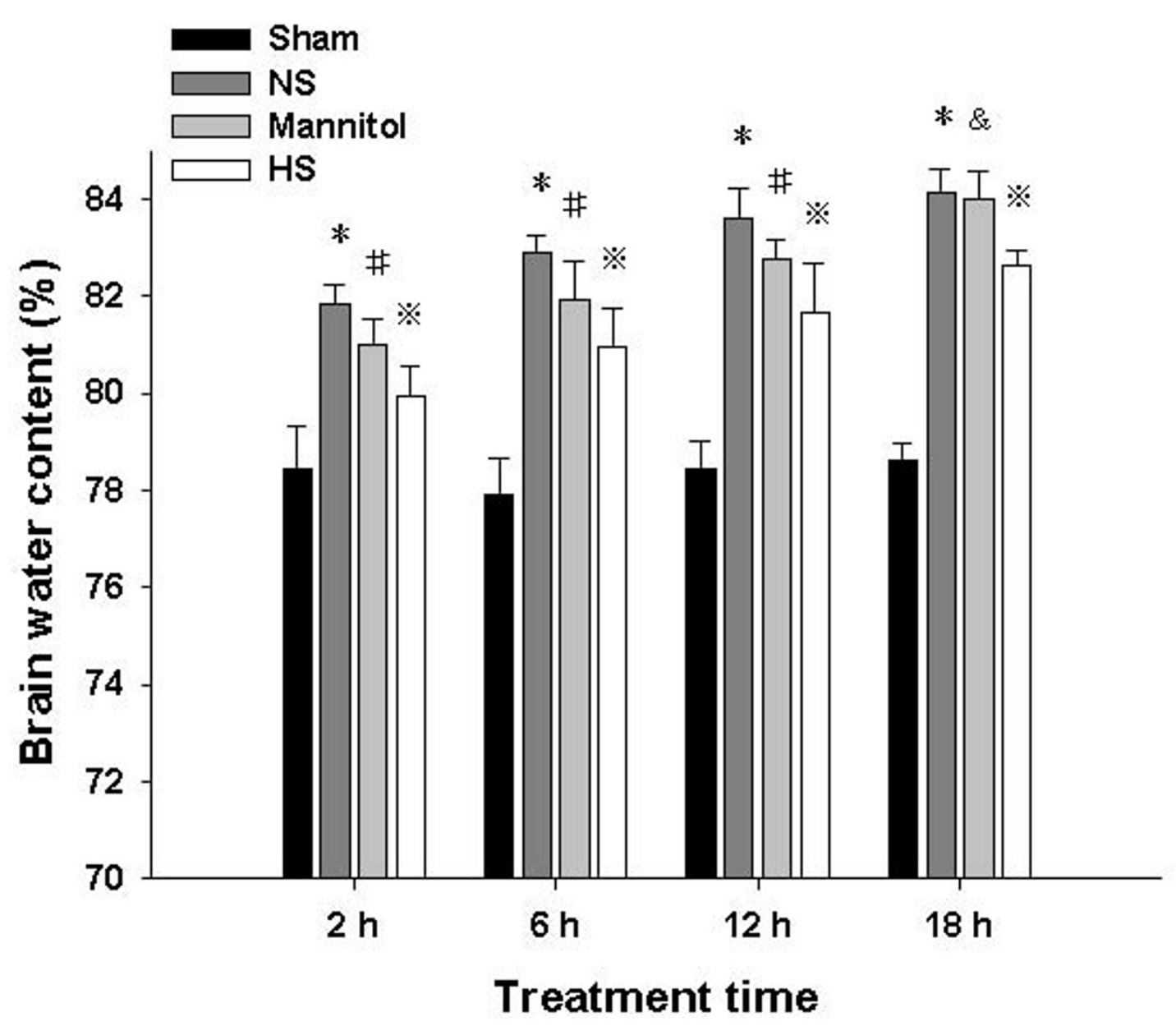

Figure 1 Ipsilateral ischemic hemispheric BWC. BWC(\%) in the ipsilateral ischemic hemisphere of the normal saline group, 20\% mannitol group and 10\% HS group at 2, 6, 12 and $18 \mathrm{~h}$ following permanent MCAO and the corresponding sham operated group. Bar graph shows that the percentage of BWC is significantly increased in the ipsilateral ischemic hemisphere of the normal saline group, 20\% mannitol group and $10 \%$ $\mathrm{HS}$ group at various time points when compared with the sham operated group ( ${ }^{*} \& p<0.05$ ). The percentage of BWC decreases significantly in the ipsilateral ischemic hemisphere at 2, 6 and $12 \mathrm{~h}$ following treatment with $20 \%$ mannitol or $10 \% \mathrm{HS}$ compared with the normal saline group $\left({ }^{\#} P<0.05,{ }^{*} P<0.05\right)$. At $18 \mathrm{~h}$, compared with the normal saline group, the percentage of BWC in the $20 \%$ mannitol does not decrease significantly $(\& P>0.05)$. However, the BWC of $10 \% \mathrm{HS}$ group continues to decrease significantly $(* P<0.05)$. BWC in the ipsilateral ischemic hemispheres of the $10 \% \mathrm{HS}$ group at 2, 6, 12 and18 h decreases significantly when compared with the $20 \%$ mannitol group ( $\left(P_{p}<0.001\right)$. 
ipsilateral ischemic hemispheres of the $20 \%$ mannitol group and the $10 \% \mathrm{HS}$ group at 2, 6 and $12 \mathrm{~h}$ decreased significantly $\left({ }^{\#}{ }_{P}<0.05\right)$. At $18 \mathrm{~h}$, however, the BWC of $20 \%$ mannitol group was not significantly different in comparison with the normal saline group $\left({ }^{\&} P=0.551\right)$. On the other hand, the BWC of $10 \%$ HS group continued to decrease and was significantly different from the normal saline group $\left({ }^{\aleph_{P}}<0.001\right)$. BWC in the ipsilateral ischemic hemispheres of the $10 \% \mathrm{HS}$ group at 2, 6, 12 and18 h decreased significantly when compared with the $20 \%$ mannitol group $\left({ }^{*} P<0.001\right)$ (Figure 1$)$.

\section{Concentration of brain $\mathrm{Na}^{+}$of ischemic hemisphere, serum $\mathrm{Na}^{+}$and plasma crystal osmotic pressure}

Analysis of concentration of brain $\mathrm{Na}^{+}$of ischemic hemisphere revealed that in the normal saline group, $20 \%$ mannitol group and the 10\% HS group at 2, 6, 12 and $18 \mathrm{~h}$ following permanent MCAO, it was increased significantly when compared with that in the sham operated group $\left({ }^{\#} P<0.001\right)$ (Figure $\left.2 \mathrm{~A}\right)$. The concentration of brain $\mathrm{Na}^{+}$in the $10 \% \mathrm{HS}$ was not increased significantly when compared with that of the normal saline group and $20 \%$ mannitol group $\left({ }^{*} \mathrm{P}>0.05\right)$ (Figure $2 \mathrm{~A}$ ). Analysis of concentration of serum $\mathrm{Na}^{+}$revealed that in the $10 \%$ HS group at 2, 6, 12 and $18 \mathrm{~h}$ following permanent MCAO, it was increased significantly when compared with that in the sham operated group, the normal saline group and the $20 \%$ mannitol group $\left({ }^{\#} P<0.001\right)$ (Figure 2B). The concentration of serum $\mathrm{Na}^{+}$in the $10 \%$ HS was not significantly different between the various time points $(F=0.381, P=0.767)$ (Figure $2 \mathrm{~B})$. Analysis of plasma crystal osmotic pressure revealed that in the $10 \% \mathrm{HS}$ group at 2, 6, 12 and $18 \mathrm{~h}$ following permanent $\mathrm{MCAO}$, it was increased significantly when compared with that in the sham operated group, the normal saline group and the $20 \%$ mannitol group $\left({ }^{\#} P<0.01\right)$ (Figure $2 \mathrm{C})$. The plasma crystal osmotic pressure in the $10 \% \mathrm{HS}$ did not differ significantly between various time points $(F=0.341, P=0.796)$ (Figure $2 \mathrm{C})$. Furthermore, additional analysis of the difference value in concentration of serum $\mathrm{Na}^{+}$and $\mathrm{Na}^{+}$in ipsilateral ischemic hemisphere revealed that in the $10 \%$ HS group at 2, 6, 12 and $18 \mathrm{~h}$ following permanent MCAO, it was increased significantly when compared with the normal saline group and the $20 \%$ mannitol group $\left({ }^{\#} P<0.05\right.$ ) (Figure $2 D)$. Compared with the sham operated group, the difference value of concentration of serum $\mathrm{Na}^{+}$and brain $\mathrm{Na}^{+}$in ipsilateral ischemic hemisphere of the $10 \% \mathrm{HS}$ group at 2, 6, 12 and $18 \mathrm{~h}$ following permanent MCAO was not significantly different $\left({ }^{\#} P>0.05\right)$. Moreover, there was no difference between the normal saline group and the 20\% mannitol group at 2, 6, 12 and $18 \mathrm{~h}$ following permanent MCAO ( $\left.{ }^{\&} P>0.05\right)$ (Figure 2D). At the same time, Correlation analysis revealed that there was negative correlation between the BWC of the ipsilateral ischemic hemisphere and concentration of serum $\mathrm{Na}^{+}(\mathrm{r}=-0.811,-0.865,-0.863,-0.911$, respectively; All $P<0.05)$ and plasma crystal osmotic pressure $(\mathrm{r}=$ $-0.813,-0.888,-0.887,-0.915$, respectively; All $P<0.05$ ) in the $10 \% \mathrm{HS}$ group at 2, 6, 12 and $18 \mathrm{~h}$ following permanent MCAO.

\section{Autoradiography}

Analysis of autoradiography revealed that the number and distribution of dark silver particles in autoradiography may reflect indirectly the content and distribution of D-[1- $\left.{ }^{3} \mathrm{H}(\mathrm{N})\right]$-mannitol. Dark silver particles were sparsely distributed in the peri-infarction brain tissue at $2 \mathrm{~h}$ following administration with $\mathrm{D}-\left[1-{ }^{3} \mathrm{H}(\mathrm{N})\right]$-mannitol (Figure 3E). The silver grains appeared to increase in number from 6 to $18 \mathrm{~h}$ (Figure 3F, G, H). Compared with $2 \mathrm{~h}$, the dark silver particles were more numerous at 12 and $18 \mathrm{~h}$ (Figure 3G, H) suggesting that mannitol was progressively accumulated in the ipsilateral infarcted region. Likewise, the incidence of the silver particles increased continuously in the corresponding nonischemic brain tissue from 2 to $18 \mathrm{~h}$ (Figure $3 \mathrm{~A}, \mathrm{~B}, \mathrm{C}$, D), notably at 12 and $18 \mathrm{~h}$ (Figure 3C, D). Results of actual particle count showed that the number of dark silver particles in the pre-infarction brain tissue and the corresponding areas in the non-ischaemic tissue increased from 2 to $18 \mathrm{~h}$ after administration with D-[1$\left.{ }^{3} \mathrm{H}(\mathrm{N})\right]$-mannitol $(P<0.01)$. The number of the silver particles in the non-ischemic brain tissue was less than that in the ischemic brain tissue at 6,12 and $18 \mathrm{~h}\left({ }^{*} \mathrm{P}<\right.$ 0.01) (Figure 3I).

\section{Concentration of $\mathrm{D}-\left[1{ }^{3} \mathrm{H}(\mathrm{N})\right]$-mannitol in the peri- infarction brain tissue and corresponding non-ischemic brain tissue}

Analysis of liquid scintillation method revealed that the concentration of D-[1- $\left.{ }^{3} \mathrm{H}(\mathrm{N})\right]-$ mannitol in the periinfarction brain tissue increased progressively from 2 to $18 \mathrm{~h}$ after administration with $\mathrm{D}-\left[1-{ }^{3} \mathrm{H}(\mathrm{N})\right]$-mannitol. It increased notably at $18 \mathrm{~h}$ in comparison with that at 2 , 6 and $12 \mathrm{~h}\left({ }^{\&} P<0.001\right)$ (Figure 4$)$. This indicates that mannitol continued to accumulate in the ipsilateral infarcted region. The concentration of D- $\left[1-{ }^{3} \mathrm{H}(\mathrm{N})\right]-$ mannitol was also progressively increased in the corresponding non-ischemic hemisphere brain tissue from 2 to $18 \mathrm{~h}$. Compared with $2 \mathrm{~h}$, the concentration of D-[1$\left.{ }^{3} \mathrm{H}(\mathrm{N})\right]$-mannitol did not increase significantly at $6 \mathrm{~h}$ in the peri-infarction brain tissue and corresponding nonischemic brain tissue $(P=0.064)$ (Figure 4$)$. However, increase at 12 and $18 \mathrm{~h}$ in comparison with $6 \mathrm{~h}$ was significant $\left({ }^{\mathbb{S}} P<0.001\right)$ (Figure 4$)$. The concentration of D$\left[1-{ }^{3} \mathrm{H}(\mathrm{N})\right]-$ mannitol in the peri-infarction brain tissue increased significantly at 12 and $18 \mathrm{~h}$ when compared 

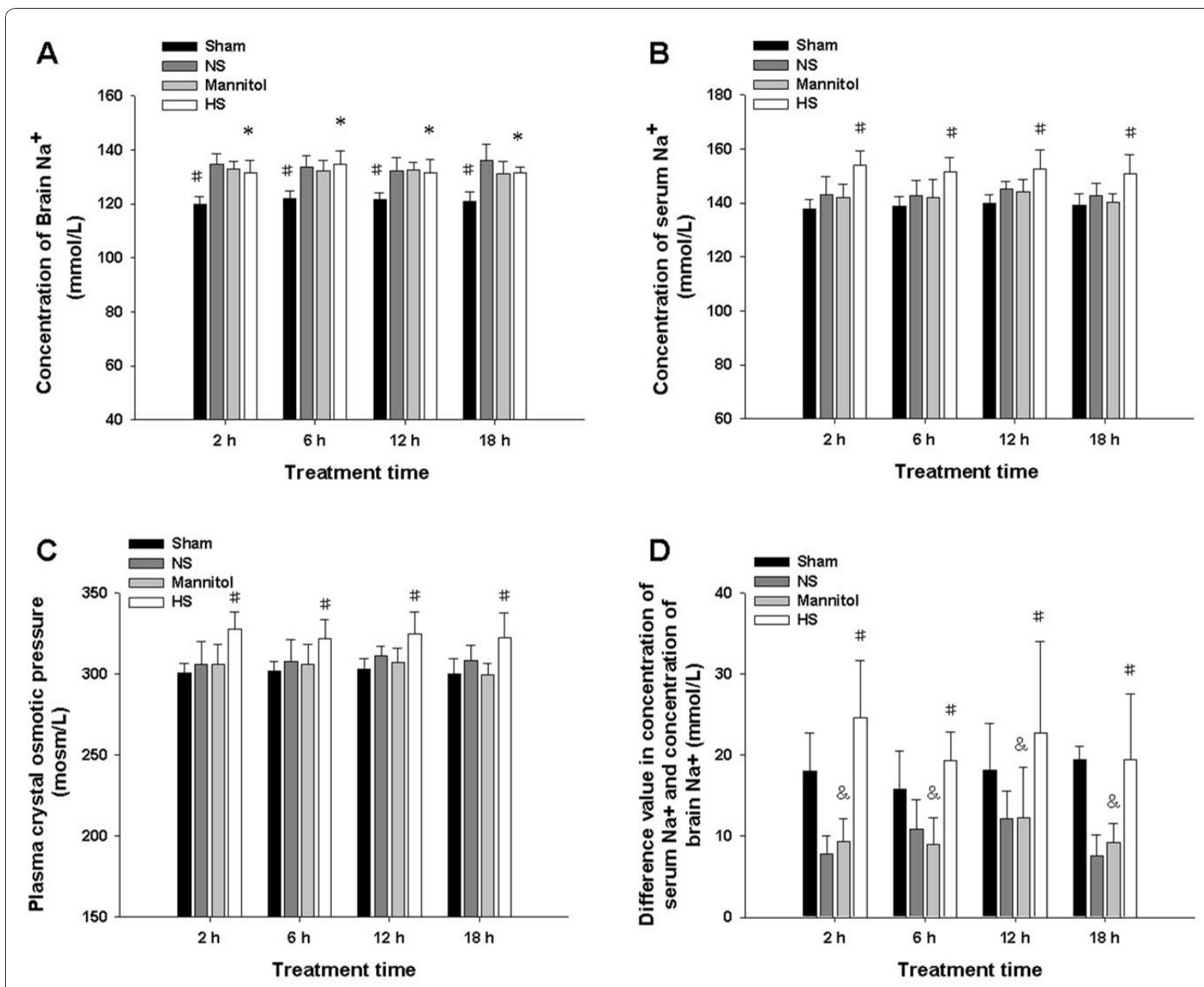

Figure 2 Plasma crystal osmotic pressure, brain $\mathrm{Na}^{+}$concentration, serum $\mathrm{Na}^{+}$concentration and difference value of both. $\mathrm{Na}^{+}$ concentration of the ipsilateral ischemic hemispheres (A), serum $\mathrm{Na}^{+}$concentration (B), plasma crystal osmotic pressure (C) and difference value in concentration of serum $\mathrm{Na}^{+}$and concentration of brain $\mathrm{Na}^{+}$in ipsilateral ischemic hemisphere (D) of the normal saline group, the $20 \%$ mannitol group and 10\% HS group at 2, 6, 12 and18 $\mathrm{h}$ following permanent MCAO as well as matching sham operated group

with corresponding non-ischemic hemisphere brain tissue $\left({ }^{*} P<0.05\right)$ (Figure 4$)$.

\section{Discussion}

HS alleviates cerebral edema and lowers ICP by establishing an osmotic gradient between the intracellular and intravascular space [22]. It has been widely used for the treatment of cerebral edema and elevated intracranial pressure (ICP) resulting from cerebral infarction $[13,23]$, hemorrhage [24] or traumatic brain injury $[25,26]$. Studies have shown that when compared with equal volume of mannitol, HS solutions may be more effective in lowering elevated ICP [27]. HS at 7.5\% showed a higher increase in serum osmolality at $15 \mathrm{~min}$ after administration than 20\% mannitol [28]. But, cerebrospinal fluid, mean arterial pressure and central venous pressure were not different between the $7.5 \% \mathrm{HS}$ and $20 \%$ mannitol treatment [28]. In both pediatric and adult traumatic brain injury (TBI), HS has been used effectively to reduce elevated ICP which is refractory to mannitol administration $[25,26]$. This study has shown that BWC in the ipsilateral ischemic hemispheres of the $20 \%$ mannitol group and the 10\% HS group at 2, 6 and $12 \mathrm{~h}$ following permanent MCAO decreased significantly when compared with that in the normal saline group. However, when compared with BWC of the normal saline group at $18 \mathrm{~h}$, the BWC of $20 \%$ mannitol group was not reduced, but the BWC of $10 \%$ HS group was decreased significantly. BWC in the ipsilateral ischemic hemispheres of the $10 \%$ HS group at 2, 6, 12 and $18 \mathrm{~h}$ decreased significantly when compared with the $20 \%$ mannitol group. BWC can reflect the degree of 

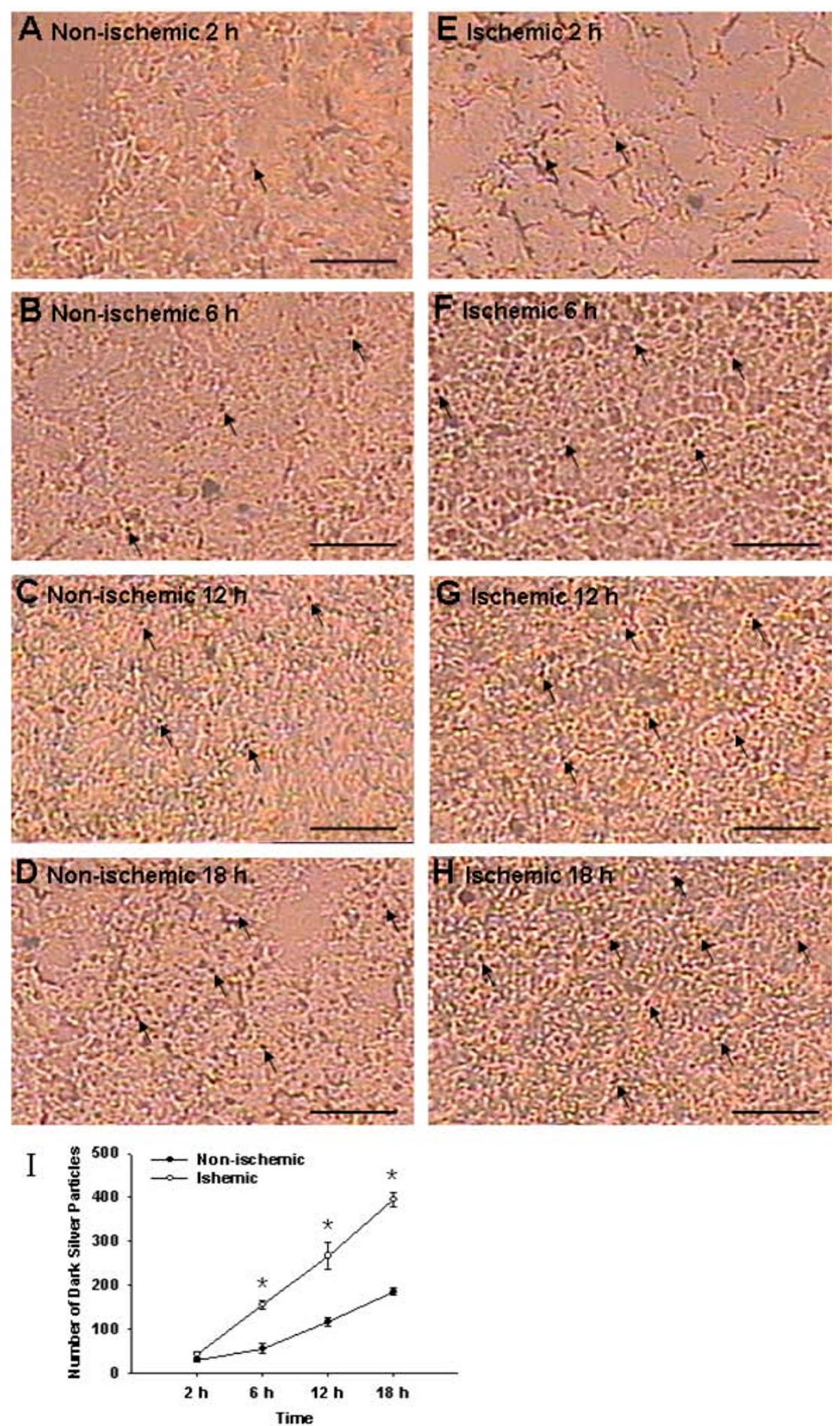

Figure 3 Autoradiography in the peri-infarction brain tissue and the corresponding areas in the non-ischemic tissue. Autoradiography shows the number of black silver particles in the peri-infarction brain tissue. The number of black silver particles increases from 2 to $18 \mathrm{~h}$ after administration with $D-\left[1-{ }^{3} H(N)\right]$-mannitol $(E, F, G, H)$ in comparison with the corresponding areas in the non-ischemic tissue $(A, B, C, D)$ being more marked at 12 and $18 \mathrm{~h}(\mathrm{G}, \mathrm{H})$. The number of dark silver particles also increases in the non-ischemic brain tissue from 2 to $18 \mathrm{~h}$ ( $\mathrm{A}, \mathrm{B}, \mathrm{C}$, D), notably at 12 and $18 \mathrm{~h}(\mathrm{C}, \mathrm{D})$, but the number of particles is evidently less than that in the ischemic brain tissue at corresponding time points. Figure $3 \mathrm{l}$ shows a significant increase in the black silver particles in the peri-infarction brain tissue at 6,12 and $18 \mathrm{~h}$ following permanent MCAO. Scale bars: A-H, $20 \mu \mathrm{m}$. 


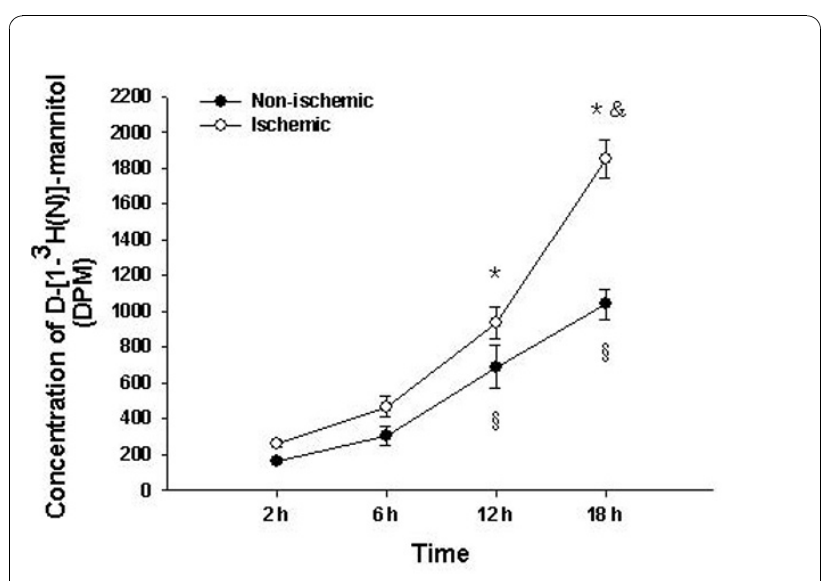

Figure 4 Concentrations of $D-\left[1-{ }^{3} H(N)\right]-m a n n i t o l$ in the ischemic and non-ischemic brain tissue. Concentrations of D-[1$\left.{ }^{3} \mathrm{H}(\mathrm{N})\right]$-mannitol in the ischemic and non-ischemic brain tissue at 6 , 12 and $18 \mathrm{~h}$ following permanent MCAO. Note the progressive increase in concentration of $\mathrm{D}-\left[1{ }^{-3} \mathrm{H}(\mathrm{N})\right]$-mannitol in the periinfarction brain tissue continuously from 2 to $18 \mathrm{~h}$ after administration with D-[1- $\left.{ }^{3} \mathrm{H}(\mathrm{N})\right]$-mannitol as detected by liquid scintillation analyzer.

brain edema $[29,30]$. Hence, the present results suggest that $10 \%$ HS is more effective in treatment of cerebral edema when compared with the $20 \%$ mannitol.

$\mathrm{Na}^{+}$ions increased commonly in the cerebral edema region, with a concomitant decrease in $\mathrm{K}^{+}$ions [31,32]. The increase in $\mathrm{Na}^{+}$ions may be attributed to reduced brain tissue spaces resulted from cerebral edema and, furthermore, the $\mathrm{Na}^{+}$ions are not reabsorbed because of obstruction of CSF reflux [32]. In addition, the activation of corresponding ion channels such as NKCC1 plays an important role in increasing the concentration of $\mathrm{Na}^{+}$ions in ischemic cerebral tissue [33-35]. Another possible explanation would be that $\mathrm{Na}^{+}$ions enter the cerebral parenchyma via increased $\mathrm{BBB}$ permeability caused by BBB breakdown. This study has shown that the concentration of $\mathrm{Na}^{+}$ions in ipsilateral ischemic hemisphere in the normal saline group, $10 \%$ HS group and $20 \%$ mannitol group increases significantly. However, $\mathrm{Na}^{+}$concentration in the $10 \%$ HS group was not significantly different from the normal saline group and the 20\% mannitol group. These results demonstrated that $10 \%$ HS administration did not cause an abnormal accumulation of $\mathrm{Na}^{+}$in the brain tissue. The reason may be that $10 \% \mathrm{HS}$ does not aggravate BBB breakdown [36].

The formula for plasma crystal osmotic pressure is as follows: plasma crystal osmolality $(\mathrm{mosm} / \mathrm{L})=2[\mathrm{Na}$ $\left.{ }^{+}(\mathrm{mmol} / \mathrm{L})+\mathrm{K}^{+}(\mathrm{mmol} / \mathrm{L})\right]+\mathrm{BUN}(\mathrm{mmol} / \mathrm{L})+\mathrm{Glu}$ $(\mathrm{mmol} / \mathrm{L})$. It is suggested from the formula that $\mathrm{Na}{ }^{+}$ ions play an important role in the maintenance of plasma crystal osmotic pressure. In this connection, if the concentration of serum $\mathrm{Na}^{+}$increases, the plasma crystal osmotic pressure will be inevitably increased. In addition, the $\mathrm{Na}^{+}$ions have been reported to play a major role in the maintenance of homeostasis and osmotic pressure balance inside and outside cells $[37,38]$. The same is true in the brain in which $\mathrm{Na}^{+}$ions imbalances are bound to lead to the osmotic pressure imbalance inside and outside cells and the cerebrovascular system [39]. Therefore, the difference value of concentration of serum $\mathrm{Na}^{+}$and concentration of brain $\mathrm{Na}^{+}$ reflect indirectly the osmotic pressure gradient inside and outside the BBB. The present results have shown that the concentration of serum $\mathrm{Na}^{+}$or plasma crystal osmotic pressure in the 10\% HS group at 2, 6, 12 and $18 \mathrm{~h}$ increased significantly when compared with that in the other groups. Moreover, compared with other groups, the difference value of concentration of serum $\mathrm{Na}^{+}$and concentration of brain $\mathrm{Na}^{+}$in ipsilateral ischemic hemisphere in 10\% HS group was increased significantly. Further analysis showed that not only there was negative correlation between the BWC of the ipsilateral ischemic hemisphere and concentration of serum $\mathrm{Na}^{+}$or plasma crystal osmotic pressure, but also there was negative correlation between the BWC of the ischemic hemisphere and the difference value of concentration of serum $\mathrm{Na}^{+}$and concentration of brain $\mathrm{Na}^{+}$in ipsilateral ischemic hemisphere in the 10\% HS group at 2, 6, 12 and $18 \mathrm{~h}$ following permanent MCAO. Therefore, it is speculated that one of the reasons that $10 \%$ HS can ameliorate the cerebral edema more effectively than $20 \%$ mannitol may be because it can maintain a higher osmotic pressure gradient inside and outside the BBB.

This study has also shown that D- $\left[1-{ }^{3} \mathrm{H}(\mathrm{N})\right]$-mannitol tends to accumulate in the ischemic cerebral hemisphere and the non-ischemic cerebral hemisphere, being most pronounced at $18 \mathrm{~h}$. It is noteworthy that the effect of $20 \%$ mannitol in ameliorating the cerebral edema was weakened significantly at $18 \mathrm{~h}$. A possible explanation for this would be that mannitol leaks through the disrupted BBB continuously and accumulates in the brain parenchyma, so that the osmotic pressure gradient inside and outside of the BBB is decreased or even reversed. This would weaken its effect in ameliorating the cerebral edema and may even aggravate the latter. Kaufmann and Cardoso [40] and Cho et al [41] reported that mannitol accumulated constantly in the injured cerebral hemisphere when it was used repeatedly by the intravenous route, so that the osmotic pressure gradient inside and outside the BBB is reversed, thus exacerbating the cerebral edema. The reason that mannitol accumulates in the non-ischemic brain tissue may be related to increase of $\mathrm{BBB}$ permeability resulting from a variety of inflammatory mediators induced by 
ischemia, hypoxia and oxidative stress $[42,43]$ and opening of BBB by itself [44]. In an experimental animal study, it was reported that not only BBB breakdown, but also BWC of ipsilateral hemisphere increased significantly after healthy adult female Wistar rats were injected with mannitol via the left jugular vein [44]. A possible mechanism related to this may be shrinkage of vascular endothelial cells and opening of endothelial tight junctions by mannitol $[45,46]$. Undoubtedly, abnormal accumulation of $20 \%$ mannitol in the pre-ischemic cerebral hemisphere and the non-ischemic cerebral hemisphere offset an osmotic pressure gradient inside and outside the BBB induced by mannitol. These also help to explain the facts that mannitol is less effective to ameliorate cerebral edema and intracranial hypertension when compared with HS.

\section{Conclusions}

This study has shown that 10\% HS is more effective in alleviating cerebral edema compared with equal volume of $20 \%$ mannitol. The following are possible mechanisms: 1) a higher osmotic pressure gradient is established by $10 \%$ HS across the BBB; 2) mannitol tends to accumulate progressively in the brain tissue and more severely in the ischemic cerebral hemisphere than the non-ischemic cerebral hemisphere with continuous intravenous injection of $20 \%$ mannitol. Undoubtedly, this will counteract the therapeutic efficacy of $20 \%$ mannitol on cerebral edema.

\begin{abstract}
Abbreviations
BBB: blood-brain barrier; BWC: brain water content: CCA: common carotid artery; CSF: cerebrospinal fluid; ECA: external carotid artery; HS: hypertonic saline; ICP: intracranial pressure; ICA: internal carotid artery; MCA: middle cerebral artery; MCAO: middle cerebralartery occlusion; SD: Sprague-Dawley.
\end{abstract}

\section{Acknowledgements}

This study was supported by Science and Technology Foundation of Guangdong Province (2007B031501005) and the Natural Science Foundation of Guangdong Province (8151008004000010). The authors would like to thank Professors HanPing Lu and JinHui Gao for technical assistance.

\section{Author details}

${ }^{1}$ Department of Emergency \& Critical Care Medicine, Guangdong General Hospital, Guangdong Academy of Medical Sciences, Guangzhou 510080, PR China. ${ }^{2}$ Department of Critical Care Medicine, The First Affiliated Hospital, University of South China, Hengyang 421001, Hunan Province, PR China. ${ }^{3}$ Graduate School, Southern Medical University, 1838 North Guangzhou Avenue, Guangzhou 510515, PR China.

\section{Authors' contributions}

ZHK carried out the design of the study and performed the statistical analysis. WQS carried out assessment of the non-ischemic and ischemic hemisphere $\mathrm{D}-\left[1-{ }^{3} \mathrm{H}(\mathrm{N})\right]$-mannitol content by autoradiography and liquid scintillation method, collected data and drafted the manuscript. DYY participated in the design of the study and drafted the manuscript. JWQ carried out assessment of ischemic hemispheric brain edema. FM participated in assessment of concentration of brain $\mathrm{Na}^{+}$of ischemic hemisphere, serum $\mathrm{Na}^{+}$and plasma crystal osmotic pressure. CCB performed the statistical analysis. JX participated in making the focal brain ischemia animal model. All authors read and approved the final manuscript.

\section{Competing interests}

The authors declare that they have no competing interests.

Received: 20 September 2010 Accepted: 10 December 2010

Published: 10 December 2010

\section{References}

1. Nag S, Manias UL, Stewart DJ: Pathology and new players in the pathogenesis of brain edema. Acta Neuropathol 2009, 118:197-217.

2. Boulard G, Marguinaud E, Sesay M: Osmotic cerebral oedema: the role of plasma osmolarity and blood brain barrier. Ann Fr Anesth Reanim 2003, 22:215-9.

3. Pérez-Pérez AJ, Pazos B, Sobrado J, Gonzalez L, Gándara A: Acute renal failure following massive mannitol infusion. Am J Nephrol 2002, 22:573-575.

4. van Hengel P, Nikken JJ, de Jong GM, Hesp WL, van Bommel EF: Mannitolinduced acute renal failure. Neth J Med 1997, 50:21-24.

5. Huang SJ, Chang L, Han YY, Lee YC, Tu YK: Efficacy and safety of hypertonic saline solutions in the treatment of severe head injury. Surg Neurol 2006, 65:539-546.

6. Kerwin AJ, Schinco MA, Tepas JJ, Renfro WH, Vitarbo EA, Muehlberger M: The use of $23.4 \%$ hypertonic saline for the management of elevated intracranial pressure in patients with severe traumatic brain injury: a pilot study. J Trauma 2009, 67:277-282.

7. Ware ML, Nemani VM, Meeker M, Lee C, Morabito DJ, Manley GT: Effects of $23.4 \%$ sodium chloride solution in reducing intracranial pressure in patients with traumatic brain injury: a preliminary study. Neurosurgery 2005, 57:727-736.

8. Battison C, Andrews PJ, Graham C, Petty T: Randomized, controlled trial on the effect of a $20 \%$ mannitol solution and a $7.5 \%$ saline $/ 6 \%$ dextran solution on increased intracranial pressure after brain injury. Crit Care Med 2005, 33:196-202, 257-258.

9. Schwarz S, Schwab S, Bertram M, Aschoff A, Hacke W: Effects of hypertonic saline hydroxyethyl starch solution and mannitol in patients with increased intracranial pressure after stroke. Stroke 1998, 29:1550-1555.

10. Schwarz S, Georgiadis D, Aschoff A, Schwab S: Effects of hypertonic (10\%) saline in patients with raised intracranial pressure after stroke. Stroke 2002, 33:136-140.

11. Tseng MY, Al-Rawi PG, Czosnyka M, Hutchinson PJ, Richards H, Pickard JD, Kirkpatrick PJ: Enhancement of cerebral blood flow using systemic hypertonic saline therapy improves outcome in patients with poorgrade spontaneous subarachnoid hemorrhage. J Neurosurg 2007, 107:274-282.

12. Toung TJ, Hurn PD, Traystman RJ, Bhardwaj A: Global brain water increases after experimental focal cerebral ischemia: effect of hypertonic saline. Crit Care Med 2002, 30:644-649.

13. Toung TJ, Tyler B, Brem H, Traystman RJ, Hurn PD, Bhardwaj A: Hypertonic saline ameliorates cerebral edema associated with experimental brain tumor. J Neurosurg Anesthesiol 2002, 14:187-193.

14. Silva JC, de de Melo TLF, Valenca MM: Hypertonic saline more efficacious than mannitol in lethal intracranial hypertension model. Neurol Res 2009, 32:139-43.

15. Harutjunyan L, Holz C, Rieger A, Menzel M, Grond S, Soukup J: Efficiency of $7.2 \%$ hypertonic saline hydroxyethyl starch $200 / 0.5$ versus mannitol $15 \%$ in the treatment of increased intracranial pressure in neurosurgical patients - a randomized clinical trial [ISRCTN62699180]. Crit Care 2005, 9: R530-R540.

16. Vialet $R$, Albanèse J, Thomachot $L$, Antonini F, Bourgouin A, Alliez B, Martin $C$ : Isovolume hypertonic solutes (sodium chloride or mannitol) in the treatment of refractory posttraumatic intracranial hypertension: 2 $\mathrm{mL} / \mathrm{kg} 7.5 \%$ saline is more effective than $2 \mathrm{~mL} / \mathrm{kg} 20 \%$ mannitol. Crit Care Med 2003, 31:1683-1687.

17. Koenig MA, Bryan M, Lewin JL, Mirski MA, Geocadin RG, Stevens RD: Reversal of transtentorial herniation with hypertonic saline. Neurology 2008, 70:1023-1029.

18. Longa EZ, Weinstein PR, Carlson S, Cummins R: Reversible middle cerebral artery occlusion without craniectomy in rats. Stroke 1989, 20:84-91.

19. Alkayed NJ, Harukuni I, Kimes AS, London ED, Traystman RJ, Hurn PD: Gender-linked brain injury in experimental stroke. Stroke 1998, 29:159-166. 
20. Thiagarajah JR, Papadopoulos MC, Verkman AS: Noninvasive early detection of brain edema in mice by near-infrared light scattering. $J$ Neurosci Res 2005, 80:293-299.

21. Manley GT, Binder DK, Papadopoulos MC, Verkman AS: New insights into water transport and edema in the central nervous system from phenotype analysis of aquaporin-4 null mice. Neuroscience 2004, 129:983-991.

22. Suarez Jl: Hypertonic saline for cerebral edema and elevated intracrania pressure. Cleve Clin J Med 2004, 71:9-13.

23. Zeng HK, Wang QS, Deng $Y Y$, Fang $M$, Chen CB, Fu YH, Jiang WQ, Jiang $X$ Hypertonic saline ameliorates cerebral edema through downregulation of aquaporin-4 expression in the astrocytes. Neuroscience 2010, 166:878-85.

24. Qureshi Al, Wilson DA, Traystman RJ: Treatment of elevated intracranial pressure in experimental intracerebral hemorrhage: comparison between mannitol and hypertonic saline. Neurosurgery 1999, 44:1055-63.

25. Peterson B, Khanna S, Fisher B, Marshall L: Prolonged hypernatremia controls elevated intracranial pressure in head-injured pediatric patients. Crit Care Med 2000, 28:1136-43.

26. Khanna S, Davis D, Peterson B, Fisher B, Tung H, O'Quigley J, Deutsch R: Use of hypertonic saline in the treatment of severe refractory posttraumatic intracranial hypertension in pediatric traumatic brain injury. Crit Care Med 2000, 28:1144-51.

27. Ziai WC, Toung TJ, Bhardwaj A: Hypertonic saline: first-line therapy for cerebral edema? J Neurol Sci 2007, 261:157-66.

28. Gemma M, Cozzi S, Tommasino C, Mungo M, Calvi MR, Cipriani A Garancini MP: $7.5 \%$ hypertonic saline versus $20 \%$ mannitol during elective neurosurgical supratentorial procedures. J Neurosurg Anesthesiol 1997, 9:329-34

29. Menzies SA, Betz AL, Hoff JT: Contributions of ions and albumin to the formation and resolution of ischemic brain edema. J Neurosurg 1993, 78:257-266.

30. Sprumont $P$, Caprano G, Lintermans J: Morphometrical quantification of brain edema related to experimental multiple micro-infarcts in mice: assessment of neurotropin effect. Methods Find Exp Clin Pharmacol 1993, 15:169-177.

31. Sun BL, Zhang SM, Xia ZL, Yang MF, Yuan H, Zhang J, Xiu RJ: The effects of nimodipine on regional cerebral blood flow, brain water and electrolyte contents in rats with subarachnoid hemorrhage. Clin Hemorheol Microcirc 2003, 29:337-344.

32. Lo WD, Betz AL, Schielke GP, Hoff JT: Transport of sodium from blood to brain in ischemic brain edema. Stroke 1987, 18:150-157.

33. Foroutan S, Brillault J, Forbush B, O'Donnell ME: Moderate-to-severe ischemic conditions increase activity and phosphorylation of the cerebral microvascular endothelial cell $\mathrm{Na}+-\mathrm{K}+-\mathrm{Cl}$ - cotransporter. Am J Physiol Cell Physiol 2005, 289:C1492-C1501.

34. Chen H, Luo J, Kintner DB, Shull GE, Sun D: Na (+)-dependent chloride transporter (NKCC1)-null mice exhibit less gray and white matter damage after focal cerebral ischemia. J Cereb Blood Flow Metab 2005, 25:54-66.

35. Simard JM, Kahle KT, Gerzanich V: Molecular mechanisms of microvascular failure in central nervous system injury-synergistic roles of NKCC1 and SUR1/TRPM4. J Neurosurg 2010, 113:622-9.

36. Chen $\mathrm{CH}$, Toung TJ, Sapirstein A, Bhardwaj A: Effect of duration of osmotherapy on blood-brain barrier disruption and regional cerebral edema after experimental stroke. J Cereb Blood Flow Metab 2006, 26:951-958.

37. Edelman IS, Leibman J, O'Meara MP, Birkenfeld LW: Interrelations between serum sodium concentration, serum osmolarity and total exchangeable sodium, total exchangeable potassium and total body water. J Clin Invest 1958, 37:1236-1256.

38. Nguyen MK, Kurtz I: Are the total exchangeable sodium, total exchangeable potassium and total body water the only determinants of the plasma water sodium concentration? Nephrol Dial Transplant 2003, 18:1266-1271.

39. Tani E, Ametani T, Handa H: Sodium localition in the adult brain. I. Normal brain tissue. Acta Neuropathol 1969, 14:137-150.

40. Kaufmann AM, Cardoso ER: Aggravation of vasogenic cerebral edema by multiple-dose mannitol. J Neurosurg 1992, 77:584-589.
41. Cho J, Kim YH, Han HS, Park J: Accumulated mannitol and aggravated cerebral edema in a rat model of middle cerebral artery infarction. $J$ Korean Neurosurg Soc 2007, 42:337-341.

42. Abbott NJ: Inflammatory mediators and modulation of blood-brain barrier permeability. Cell Mol Neurobiol 2000, 20:131-147.

43. Hariri RJ: Cerebral edema. Neurosurg Clin N Am 1994, 5:687-706.

44. Kaya M, Gulturk S, Elmas I, Kalayci R, Arican N, Kocyildiz ZC, Kucuk M, Yorulmaz $\mathrm{H}$, Sivas A: The effects of magnesium sulfate on blood-brain barrier disruption caused by intracarotid injection of hyperosmolar mannitol in rats. Life Sci 2004, 76:201-212.

45. Quencer RM, Neuwelt EA: Advances in the understanding of the bloodbrain barrier in neuro-oncology. AJNR Am J Neuroradiol 2002, 23:1807-1810.

46. Rapoport SI: Osmotic opening of the blood-brain barrier: principles, mechanism, and therapeutic applications. Cell Mol Neurobiol 2000, 20:217-230.

doi:10.1186/1471-2202-11-153

Cite this article as: Zeng et al: A comparative study on the efficacy of $10 \%$ hypertonic saline and equal volume of $20 \%$ mannitol in the treatment of experimentally induced cerebral edema in adult rats. BMC Neuroscience 2010 11:153.

\section{Submit your next manuscript to BioMed Central and take full advantage of:}

- Convenient online submission

- Thorough peer review

- No space constraints or color figure charges

- Immediate publication on acceptance

- Inclusion in PubMed, CAS, Scopus and Google Scholar

- Research which is freely available for redistribution

Submit your manuscript a www biomedcentral.com/submit
Biomed Central 